\title{
Languaging, Irony, and Bottomless Bottoms
}

\author{
A Response to Ton Jörg’s Programmatic View
}

\section{BRENT DAVIS}

University of British Columbia (Canada)

I write this in early-December. It's cool outside ... raining, but (so says the radio announcer, between Christmas songs) snowing heavily in the nearby mountains. That's good news. We're planning to go skiing during the upcoming break.

There's a fire going. The dog is curled up a careful distance from its heat. The fauxtree outside the window is aglow with curiously-calming-blue LED lights.

Every now and then I catch myself humming along to the music, but for the most part the seasonal tunes dissolve into the background. Present but not. Pa rum pum pum pum. Things are as they should be.

Ah, the comfort of inhabiting this space of things being as they should ... this collective hallucination woven and sustained by predecessors and contemporaries, known and unknown. It is all the more precious when a few other hallucinations boundless growth, stable economies, and sound government among them - seem to be unraveling around us. Yes, of course I'm aware how easily these co-constructs can be deconstructed, how so many aspects of the world described above are really little more than simulacra, how the collision of cultures and climates has transformed one of the defining annual events of a major mono(lithic)theism into a truly postmodern pastiche. Sometimes I even acknowledge my/our obligation to interrogate the entailments of the sort of mindless participation that I report in the previous paragraphs. I am complicit in what I critique. 


\section{Languaging}

Perhaps it is true, then, that the eye will never see itself at work, as Vico noted and as Ton Jörg reminds us. But I can't help but wonder if this is a matter of can't or won't.

Among many important points, I believe that Ton is suggesting that, with complexity thinking, the situation is coming to be more a matter of won't. With complexity discourses, we have come upon - that is, invented, in its original sense - a technology that enables gazers to gaze upon their gazing.

But how new is this capacity? Not very, I'm told. It seems to be something that is made possible by the ancient technology of language. Or, more accurately, languaging. As Maturana (1988) described it, languaging is a special capability, recursive to its core, able to turn on and elaborate itself. More than just a coordination of action, in Maturana's terms, languaging might be characterized as the consensual coordination of [the consensual coordination of [the consensual coordination of [action]]]. Insert extra nested levels as necessary, until the eye/I-in-action comes into clear focus of the eye/I(it)self ...

... or, as it were, until the languaging of science comes into clear view of sciencing.

So, two points, really: I'm guessing that the linguistic technology needed for the eye/I to see itself at work has been around for a while. What has not been broadly represented is a sensibility, a mindset, an inclination to engage with that technology on a grand scale. So, in essence, I think I'm both agreeing with and departing from Ton's discussion. I share his optimism that complexity and its associated discourses (including, but certainly not limited to cybernetics, systems theory, non-linear dynamics, and deep ecology) might help to prompt education, specifically, and western cultures, generally, toward a more expansive and participatory consciousness - a mode of being that was so powerfully and concisely articulated by Cohen and Stewart (1995) in the notion of complicity (cf. Davis, Phelps, \& Wells, 2004).

\section{Irony}

None of this is news, of course. As a core thematic of 20th-century philosophy, it is now almost commonsensical that language structures experience, and that this language is always subject to further languaging. Rorty (1989) made the point in the three carefully chosen words of a book title: Contingency, irony, and solidarity. Throughout this collection of essays, he developed (among other thoughts) that vocabularies are always a little accidental, dependent, self-contradictory, playful, and - through all of that - unifying. It is amidst this complex phenomenon that Rorty presents the methods of the ironist:

The ironist's preferred form of argument is dialectical in the sense that she takes the unit of persuasion to be a vocabulary rather than a proposition. Her method is redescription rather than inference. Ironists specialize in redescribing ranges of objects or events in partially neologistic jargon, in the hopes that by the time she is finished using old words in new senses, not to mention introducing brand new words, people will no longer ask questions phrased in the old words. So the ironist thinks of logic as ancillary to dialectic. (p. 78) 
So, now after that bit of meandering and stage-setting, let me get to some substantive response. I must confess to having been thrown with the very first sentence of Ton's article - specifically the imperative, "we must distinguish between the fundamental and the practical" (my emphasis).

I suspect that this is one of those moments when, had we the opportunity to chat about intended meanings, problems of translation, and the like, we'd've eventually found that we were talking about the same thing.

\section{Bottomless Bottoms}

So let me comment on the snags that I encountered here, after which I attempt to tie together Ton's argument and the above text.

First, the fundamental - the lowest part, the solid base of a structure, the thing on which all other things rest. On this matter I am reminded of Laughlin's (2005) discussion of "reinventing physics from the bottom down." Laughlin simultaneously disposes of two prizes of modern science, its end (in the sense of a totalized knowledge of everything) and its fundamentals (its basic laws, particles, and so on). A Nobel laureate, Laughlin reports on the dawning realization that the most fundamental laws of physics - Newton's laws, quantum mechanics, and the like - are actually emergent, in the complexity sense. They are not fundaments, but properties of large assemblages of matter ... which itself is not what it seems. Insert extra nested emergent levels as necessary to make sense of it all.

So the fundamental is emergent. And, as any cultural theorist will tell you, so is the practical. Which is why I get stuck on Ton's first sentence, even while embracing the rest of his discussion. I'm not quite sure where to draw a line to make sense of this separation. Except, perhaps, to couple the fundamental to complexity thinking - a bottomless bottom, as it were - and the practical to the dynamic of languaging (à la Maturana) and the redescriptive method of the ironist, à la Rorty. A mode of thinking, and a mode of teaching, as it were.

That's really all that I have to say. Well, almost. I'm profoundly interested in the practical. I want to hear more from Ton on this aspect of the matter. Mindful that the ground of our action is always subject to change, aware of the contingency and fragility of our vocabularies, how do we as educators take the insights of complexity seriously without taking our selves too seriously?

On this matter, I applaud Ton's efforts to bring Vygotsky's work into the "complexity and education" conversation. This contribution is important on many levels. For example, it's a reminder that complexity thinking is an instance of itself - that is, not a new mode of interpretation, but a sort of emergent collecting place for insights that have been amassing for many, many decades. Ton's contribution is also a reminder of the subtle pragmatics of Vygotsky's work. So often treated in the educational literature more as a tool of interpretation than a means of intervention, Ton has helped me to better understand how Vygotsky actually gave educators some very practical 
advice. Unfortunately Vygotsky's practical makes little sense without an appreciation of his rejection of things foundational (in the rigid sense of the term).

Right, then, I think that I am beginning to understand. I just want to change that first sentence with one small addition:

To formulate the aim of this project on learning and education, we must distinguish between the fundamental and the practical: between the 'foundationless foundation' of a new vision about learning and the complex way learning manifests itself in the practice of education. (Jörg, this issue, p. 1, italicized word added)

And that just pushes me into similar desire to reformulate one of the closing sentences:

The dynamic complexity paradigm of thinking in complexity about reality of learning and education, and the corresponding causal modelling of this dynamic complexity will enable us to overcome the myths we live by in the field of learning and education ... and which are the result of the blind spots of mainstream thinking: the myths which may lead to what Edgar Morin has called a "perverted system of education", with its blind focus on ends .... (Jörg, this issue, p. 22)

Maybe it's only because I'm still reeling from another not-completely-successful effort to trouble commonsense theories of learning among pre-service teachers, inviting them to consider complex dynamics as an alternative window onto the phenomena of knowing, learning, and teaching. I wish I could share the confidence that "complexity will enable us to overcome myths." But my faith is eroded by both the evidence I encounter in some undergraduate classes and the anxieties associated with knowing that we inhabit hallucinations.

At the same time, I can't help but be swayed by Ton's hopeful sentiment around thoughts of "how human being may become humanized by our thinking in complexity." I've experienced that as well - much more often in working with practicing teachers than with pre-service teachers. Immersed in the complexities of learning classrooms and aware of the mutual entanglements of learners with one another and with emergent understandings, my experience is that teachers resonate with complexity. I've seen it taken on very quickly, first to describe, then to explain, then to inform lives with children. There is good reason for hope, I think. But the transition from complexity thinking and complex education is by no means obvious.

Yes, I do think that complexity is a better core than current commonsense for construing a world. Yes, I agree it has much to offer education. But I elect to be somewhat more cautious in my expressions of hope.

I thank Ton for an important, provocative, and consolidating piece of writing. I actually doubt I disagree with anything, but there's no way of knowing that until he and I have opportunity to co-construct understandings. 


\section{References}

Cohen, Jack S., \& Stewart, Ian. 1995. Collapse of chaos: Discovering simplicity in a complex world. London: Penguin.

Davis, Brent, Phelps, Renata, \& Wells, Kris. 2004. Complicity: An introduction and a welcome. Complicity: An International Journal of Complexity and Education, 1(1), 1-7.

Laughlin, Robert B. 2005. A different universe :Reinventing physics from the bottom down. New York: Basic Books.

Maturana, H. R. 1988. Ontology of observing: The biological foundations of self consciousness and the physical domain of existence. In Texts in cybernetic theory: An in-depth exploration of the thought of Humberto Maturana, William T. Powers, and Ernst von Glasersfeld. Edited by R. Donaldson. American Association for Cybernetics. Available at http://www.inteco.cl/biology/ontology/

Rorty, Richard. 1989. Contingency, irony, and solidarity. Cambridge, UK: Cambridge University Press.

\section{About the Author}

Brent Davis is Professor and David Robitaille Chair in Mathematics, Science, and Technology Education at the University of British Columbia. His research is developed around the educational relevance of developments in the cognitive and complexity sciences, and he teaches courses at the undergraduate and graduate levels in curriculum studies, mathematics education, and educational change. Davis has published books and articles in the areas of mathematics learning and teaching, curriculum theory, teacher education, epistemology, and action research. His most recent book is Engaging Minds: Changing Teaching in Complex Times (2nd edition, 2008; co-authored with Dennis Sumara and Rebecca Luce-Kapler). He is currently Editor of The Learning of Mathematics. Davis, along with Renata Phelps, was a Founding Editor of Complicity. He can be contacted at the following email address: brent.davis@ubc.ca

(C) Copyright 2009. The author, BRENT DAVIS, assigns to the University of Alberta and other educational and non-profit institutions a non-exclusive license to use this document for personal use and in courses of instruction provided that the article is used in full and this copyright statement is reproduced. The author also grants a non-exclusive license to the University of Alberta to publish this document in full on the World Wide Web, and for the document to be published on mirrors on the World Wide Web. Any other usage is prohibited without the express permission of the authors. 